\title{
(Tecno)poéticas da atividade: artesanias por entre imagem, trabalho e subjetivação
}

\section{(Techno)poetics of activity: artesanias through image, work and subjectivation}

\section{Resumo:}

Neste artigo abordamos o emprego de tecnologias digitais de imagem em pesquisas que se voltam para o tema trabalho e subjetivação. Partindo da Metodologia de Autoconfrontação Simples e Cruzada proposta em Clínica da Atividade, tecemos indagações quanto às peculiaridades da experimentação imagética na pesquisa. Apresentamos, inicialmente, a Clínica da Atividade e a metodologia da Autoconfrontação. A seguir, discutimos os percursos da imagem pelo corpo em uma conversa com Bergson e Deleuze, bem como abordamos a imagem videográfica do ponto de vista de suas particularidades tecnológicas na pesquisa da atividade. Finalizamos com o realce das imagens enquanto complexos de sensações não redutíveis à significação discursiva mas que jogam com o plano da linguagem, um papel crucial na análise da atividade de trabalho.

Palavras-chave: Imagem. Trabalho. Subjetivação.

\section{Abstract}

In this article we approach the use of digital image technologies in researches that focus on the theme labour and subjectivation. Starting from the Methodology of Simple and Crossed Self-Confrontation proposed at the Clinic of Activity, we make inquiries as to the peculiarities of visual imagery experimentation in research. At first we present the Clinic of Activity and the methodology of self-confrontation. Then we discuss the pathways of the image through the body in a conversation with Bergson and Deleuze, as well as address the video image from the viewpoint of its technological particularities in activity research. We conclude by highlighting the images considered as sensationcomplexes that play with the plane of language, instead of being reducible to discursive meaning, a crucial role in the analysis of labour activity.

Keywords: Image. Labour. Subjectivation.
AMADOR, Fernanda Spanier. (Tecno)poéticas da atividade: artesanias por entre imagem, trabalho e subjetivação. Informática na Educação: teoria \& prática, Porto Alegre, v. 13, n. 1, p. 17-30, jan./jun. 2010.

\section{Fernanda Spanier Amador \\ Universidade Federal do Rio Grande do Sul}

\section{Clínica da atividade e autoconfrontação simples e cruzada}

A Clínica da Atividade consiste em uma abordagem dentre outras no âmbito das Clínicas do Trabalho ${ }^{1}$ que se interessa por acompanhar os cursos da atividade do trabalhador em situação laboral. Falamos em cursos da atividade para sinergizar com a própria definição do termo proposta por Yves Clot, pesquisador e coordenador do Laboratório de Psicologia do Trabalho do CNAM/Paris. A atividade consiste, na realização efetiva da tarefa - por ela, mas também, por vezes, contra ela -, da recriação de meios para viver. Para Clot (2008) a atividade implica mais do que dimensões lógicas, exige dimensões poéticas por ser regida pelo signo da criação como fonte permanente de invenção. Assim, a atividade prática do sujeito não é apenas efeito das condições externas nem mesmo a resposta a estas condições e a atividade psíquica não é mais a reprodução interna destas condições, diz Clot (2008). Para ele: "L'activité - pratique et psychique - est toujours le siége d'investissements vitaux: elle transforme les

1 No escopo das Clínicas do Trabalho elencam-se perspectivas teórico-metodológicas designadas como Psicologia Social Clínica e Psicopatologia do Trabalho pelas quais se pensa em clínicas enquanto modalidades de intervenção que visam à relação trabalho, saúde, sofrimento e adoecimento mediante o enfoque de situações laborais (LHUILIER, 2006). 
objets du mond en moyen de vivre ou échoue à la faire [...]" (CLOT, 2008, p. 7).

A atividade está, então, a favor da vida no e pelo trabalho implicando a possibilidade de desenvolvê-lo, por seus objetos, por seus instrumentos, por seus destinatários e afetando a organização do trabalho (CLOT, 2008). Assim, o autor nos convoca a pensar o trabalho desde a perspectiva de um primum movens ${ }^{2}$, como nascente da ação. Nesta direção, a atividade pertence à ordem de uma vitalidade do trabaIho, como sugere Durrive:

[...] a ação tem um início e um fim determinados; ela pode ser identificada (gesto, marca), imputada a uma decisão, submetida a uma razão [...]. Já atividade é um élan de vida e de saúde3, sem limite predefinido [...] (DURRIVE, 2007, p. 19).

Clot (2008) define o que vem a ser o sentido da atividade realizada: a relação de valor que o sujeito instaura entre esta ação e suas outras ações possíveis. Ocorre, então, uma alternância funcional entre sentido e eficiência da ação na qual joga o dinamismo da atividade. Não se trata de pensar uma eficiência em termos de atingimento de objetivos a perseguir, mas de descoberta de objetivos novos. Atinge-se a renovação do sentido da ação pelo ultrapassamento dos resultados previstos através dos objetivos atendidos por meio de uma situação inesperada, isto é, pelo desenvolvimento do poder de agir. Assim, pensar o trabalho enquanto atividade, implica reconhecer, tal com o faz a Ergonomia francófona, que ele apesar de se constituir em tarefa com fins estabelecidos requerendo realizações mediatas, tanto individuais quanto coletivas, sempre lida com uma dimensão imediata da situação, que engaja e transforma, ao mesmo tempo, aquele que a executa (TEIGER, apud FERREIRA, 2000).

\footnotetext{
2 Expressão que se refere ao conatus apresentado por Spinoza. Consiste no fundamento primeiro do movimento, causa eficiente e não final.

3 Canguilhem (2001) funda o significado do normal por uma análise filosófica da vida, entendida como atividade de oposição à inércia e à indiferença. Se a vida é sempre atividade de oposição à inércia e à indiferença, isso é verdade, também, no caso da vida no trabalho. Se a vida no trabalho é tentativa de viver, ela é também tentativa de nunca somente sofrê-la, ela é tentativa de fazer valer nesse meio - nesse tecido de normas antecedentes, nesse enquadramento abstrato do trabalho -, as normas de vida oriundas da própria história daqueles que trabalham, oriundas do que é para eles viver em saúde.
}

Diz a autora:

[...] existe na atividade qualquer coisa de irredutível a qualquer previsão, a qualquer prescrição, a qualquer regularidade stricto sensu. Neste sentido, a atividade é um compromisso a ser encontrado entre uma intenção inscrita numa história e num projeto e as solicitações e exigências, ao mesmo tempo, exógenas (provenientes do ambiente material ou relacional mais ou menos estável) e endógenas (provenientes do estado funcional momentâneo não estável) (TEIGER, apud FERREIRA, 2000, p.117).

Deste modo, Teiger (apud FERREIRA, 2000) destaca um caráter de imprevisibilidade da atividade que requer a cada instante a inteligência criadora de trabalhadores e trabalhadoras. Além disto, salienta a existência de uma irredutibilidade que evidencia o enigma da atividade, enigma esse situado em uma fronteira muito pouco nítida entre um pensamento capaz de representar e solucionar problemas e aquele afeito a seguir os rastros indiscerníveis do (i) representável para abrir sendas problemáticas relativas ao trabalho, capazes de fazê-lo nascer de modos ainda não existentes.

Yves Clot (2008) ainda liga o conceito de atividade ao de métier, esse o trabalho oficial reorganizado e que apresenta quatro dimensões em ligação: Dimensão Pessoal (atividade própria do sujeito numa mesma atividade correspondendo ao modo de cultivo do ofício em mim); Dimensão Impessoal (prescrição oficial do ofício que permite às pessoas fazerem a mesma tarefa); Interpessoal (o trabalho é endereçado a alguém) e Transpessoal (memória coletiva e o subentendido para a ação). 0 movimento por essas quatro dimensões ajuda a entender a experiência do trabalho, afirma Clot (2007). Para ele, o mecanismo de desenvolvimento da experiência se dá pela transformação da passagem da prescrição oficial de objeto, em meio: um meio de fazer diferente seu trabalho, um meio de voltar-se aos outros, penetrando no gênero e ajudando-o a ser construído.

O gênero profissional não se refere a acordos interpessoais. Ele é mais do que isso. Trata-se da constituição de um ambiente cognitivo comum, de um referencial operativo comum, o qual não designa um modo formal de regulação profissional, conforme diz Clot:

Meio de ação para cada um, o gênero é também história de um grupo e memória impessoal 
de um local de trabalho [...] mas sempre se tratará das atividades ligadas a uma situação, das maneiras de 'apreender' as coisas e as pessoas num determinado meio. A esse título, como instrumento social da ação, o gênero conserva a história (CLOT, 2006, p. 38).

O gênero é o subentendido da atividade, é aquilo que os trabalhadores de um meio dado conhecem e vêem, esperam e reconhecem, apreciam ou temem. É o que lhes é comum e que os reúne em condições reais de vida, não sendo necessário reespecificar a tarefa a cada vez que ela se apresenta. Ele oferece uma forma social que re-presenta a ação permitindo, assim, sua significação. Para afiná-lo, Clot (2008) propõe o conceito de estilo. É ele, segundo o autor, que garante o desenvolvimento do gênero profissional, sua não cristalização ao introduzir variação no gênero. Ele é, paradoxalmente, o acabamento do gênero já que esse se conserva inacabado. $O$ estilo é a perturbação do gênero, é sua renovação, é seu elemento de plasticidade localizado nos pontos de colisão do gênero.

Existe uma incitação recíproca entre gênero e estilo pois o primeiro assume sua forma acabada nos traços particulares contingentes e únicos que definem cada situação de trabalho vivida. O gênero fornece recursos e protege da própria ação mas é também o limite; é o que se pode interpor entre a situação e mim mesmo (CLOT, 2006). Trata-se de uma espécie de coletivo interiorizado que dá segurança, tornandose instrumento individual e permitindo realizar a atividade.

Assim, entrar no gênero significa acolher a criação individual e deparar-se, portanto, com as variações da atividade. Comportando o esperado da situação, o gênero permite o afinamento do tom da atividade individual no coletivo. Ele mais do que compilação de modos de agir, consiste numa espécie de diapasão que afina, que ajusta, que dá o tom de ligação da diversidade possível num certo modo de agir, porém conservando-a ao invés de anulá-la.

O trabalho, para Clot (2006), implica enquanto atividade, levar em consideração a elaboração da própria tarefa, por parte do sujeito. Assumindo uma perspectiva histórico-psicológica, seu modelo não é embriológico, por levar em consideração o fato de que o desenvolvimento se dá nas situações reais, isto é, que o real se encarrega de transformar o desenvolvimento esperado em história não realiza- da. Para o autor: "A atividade é a apropriação das ações passadas e presentes de sua história pelo sujeito, fonte de uma espontaneidade indestrutível. Mesmo brutalmente proibida, nem por isso ela é abolida [...]" (CLOT, 2006, p. 14-15). O trabalho, então, remete a reutilização do que já é dado de modo a reconcebê-lo. Trata-se de instrumentar um meio para viver (CLOT, 1985).

Nesta instrumentação a linguagem figura como elemento crucial. A este respeito, diz Clot:

Pour qu'il continue à vivre (o métier) là, il faut qu'il soit vivant ailleurs. Il vit donc aussi - ou il meurt - entre professionnels et en chacun d'eux dans la motricité des dialogues où se réalisent ou non les échanges intrapersonnels et interpersonnels sur le réel du travail. (CLOT, 2008, p. 258)

Com esta passagem, o autor coloca a dimensão da linguagem, especialmente pela dialogia bakhtiniana ${ }^{4}$, na centralidade das migrações funcionais operadas no plano do métier, pela atividade que o modifica. Deriva daí a metodologia da Autoconfrontação Simples e Cruzada empregada nas pesquisas em Clínica da Atividade a qual consiste exatamente numa abordagem dialógica da atividade humana no desenvolvimento do poder de ação dos coletivos profissionais. Clot (2008) sustenta que a atividade de análise é orientada para duas dimensões: o real $^{5}$ do trabalho, como sendo aquilo que faz problema e é difícil de explicar e, para o movimento dialógico ele mesmo.

Em termos metodológicos sua abordagem coloca instigantes indagações. Para o autor (CLOT, 2006), há um momento decisivo: a singularidade para ser objeto de estudo deve integrar a compreensão de uma situação à

\footnotetext{
4 Bakhtin (1988) afirma a característica dialógica da linguagem ressaltando o caráter social da fala. Para ele, é pela interação verbal que a realidade linguística ganha existência, sendo o enunciado, parte desta interação. Assim, reconhecer a natureza dialógica da linguagem implica operar com a ideia de inacabamento enunciativo ativado pela dinâmica intersubjetiva pela qual se vai, incessantemente, de um dizer a outro dizer, recriando-o, ativamente. Desta maneira podemos tomar a própria linguagem como atividade a qual guarda intimamente com o desenvolvimento das atividades de coletivos profissionais, como assinala França (2004).

5 O Real da Atividade distingue-se do termo Trabalho Real definido pela Ergonomia. Neste, situa-se aquilo que se realiza e que se apresenta observável, enquanto o Real designa uma insistência de dimensões inobserváveis que a ultrapassam. Assim, pensamos que o Trabalho Real lança a discussão para o plano das atualizações do trabalho enquanto o Real da Atividade remete às suas virtualidades. Tal discussão acerca do real e do possível, bem como do atual e do virtual será retomada mais neste texto.
} 
unidade subjetiva e a uma experiência e não somente às representações funcionais que a experiência supõe. Situando-se no que define como ambiente habitual, o autor propõe, então, a análise da atividade pela instauração de um espaço de co-análise do trabalho, dizendo: "Ela concerne àquilo que os homens fazem com as provações pelas quais passam e das soluções que eles encontram, ou não encontram, a fim de enfrentá-las [...]" (CLOT, 2006, p. 127).

Deste modo, o objeto da análise são as condições de vida habitual num meio considerado natural, buscando acompanhar as trilhas de uma psicologia prática, essa relativa aos objetivos e às motivações dos atos humanos para renormalizar o trabalho diante dos desafios do meio. Desse modo, ela consiste numa psicologia tanto concreta quanto viva por localizar-se na zona da produção de sentido e da eficiência em situação habitual de trabalho, uma zona relativa ao pensamento em ato de homens e mulheres no trabalho, um pensamento ligado aos deslocamentos provocados pela atividade. Assim, é a singularidade da experiência no trabalho - essa entendida na perspectiva bakhtiniana como modo peculiar de cultivo do ofício em mim, como maneira estilizada de trabalhar que assumo em meu fazer - que consiste no objeto de estudo em Clínica da Atividade.

Para tanto, Clot (2006) propõe os métodos de Autoconfrontação Simples e Cruzada, as quais implicam o emprego de câmeras de vídeo para recriar artificialmente a vivência das experiências no trabalho e o pensamento que a acompanha. Proposto como método da Clínica da Atividade, apresenta três fases. $\mathrm{Na}$ primeira, realiza-se a constituição de um Meio Associado à Pesquisa formado por pesquisadores e trabalhadores para um longo trabaIho de concepção partilhada das situações a serem analisadas, incluindo observações de situações pelos próprios pesquisadores; na segunda, parte-se para a produção de documentos videografados de autoconfrontação simples (sujeito/pesquisador/imagens) e de documentos de autoconfrontação cruzada (dois sujeitos/pesquisador/imagens). Por fim, volta-se ao Meio Associado para análise e coanálise: filtragem da experiência profissional posta em discussão em termos de situações rigorosamente delimitadas. Por esse método, se estabelece um ciclo entre aquilo que os trabalhadores fazem, aquilo que eles dizem daquilo que fazem e, por fim, aquilo que eles fazem daquilo que dizem.

Ao afirmar que seu interesse recai sobre uma espécie de re-descrição da atividade mediante imagens produzidas com o emprego de câmeras de vídeo, parece-nos apontar para a busca de um pensamento sobre a ação que se transforma, como mesmo diz o autor, artificialmente à sua frente, assim como o pensamento também se modifica habitualmente ${ }^{6}$ nas situações concretas de trabalho.

No entanto, as publicações em Clínica da Atividade pouco discutem a especificidade da imagem videográfica empregada em sua metodologia, fato esse que nos leva a dedicarnos ao assunto. Para Clot (2006), o registro meticuloso pela gravação de sons e imagens dos arquivos de linguagem e técnicas da atividade real mostrou-se como uma opção metodológica bastante produtiva sendo a linguagem considerada não apenas como meio de verbalização da ação, pelo qual se põe em palavras depois do fato, mas, sobretudo, como uma atividade em seu curso, sem sentido pleno nas situações de trabalho.

Neste sentido, diz Clot:

O registro sistemático dos 'meios desviados' graças aos quais aqueles que trabalham se desincumbem das provações que a situação Ihes impõe atesta que o real da atividade ultrapassa não somente a tarefa prescrita mas também a própria atividade realizada (CLOT, 2006, p. 133).

6 A propósito do hábito, Do Eirado (1998) traz elementos importantes para pensarmos em aproximações entre o pensamento de Deleuze e as discussões acerca da atividade. Seguindo uma linha argumentativa de que o hábito não é resposta às situações e sim, problemas que formam ou constroem as situações onde vão operar, chama a atenção para dimensões, tais como: pelos hábitos também somos capazes de nos apercebermos de nossas transformações; eles consistem em produção involuntária e inconsciente de si. O autor, fundamentando-se numa concepção de repetição enquanto elemento problemático e paradoxal do hábito, destaca sua íntima relação com a diferença, por necessitar, o hábito, passar pela criação. Desse modo, Do Eirado (1998) localiza-o numa zona ontológica, anterior a qualquer atividade do sujeito e, portanto ligado à emergência do subjetivo. Diz ele: "Em todos os níveis o hábito, antes de se confundir com a aquisição de um novo comportamento, de uma nova função, exprime a invenção de uma nova experiência. E a possibilidade de tornar sensível alguma coisa totalmente estranha, disparatada e, a priori, sem sentido para nós. No lugar de nos adaptar a um meio previamente dado, ele nos permite um dehors incomensurável conosco, e assim, inventar a nós mesmos e ao mundo" (DO EIRADO, 1998, p. 3). Sendo a singularidade no curso da atividade o objeto de estudo em Clínica da Atividade, parece localizar-se, essa última também, numa zona ontológica relativa à experiência do trabalho. 
Nota-se que a ideia de Real do Trabalho como ultrapassamento do Trabalho Real põe em cena um plano de análise que a nós parece crucial, quando da pesquisa da atividade de trabalho. Trata-se do que denominamos de Trabalho Virtual (AMADOR, 2009), uma ação mínima ou devir-intenso da ação que introduz estrangeiridade no trabalho por operadores de tensão capazes de manter viva uma potência de desterritorialização da ação. Por isso, a atividade está longe de poder ser tomada enquanto objeto ao operar por resistência a categorias que a definem, de maneira que preferimos pensá-la em sua potência de fabricação permanente de si própria.

Retomando a citação de Yves Clot (2006) acerca do dispositivo videográfico na Autoconfrontação, observa-se que a ênfase metodológica, neste caso, se situa na conversação ficando a imagem videográfica reduzida a um dispositivo para acionar o debate.

Faita (2007) salienta, em texto dedicado à imagem animada como artefato no quadro metodológico de uma clínica da atividade, que por haver uma dimensão não diretamente acessível na análise da atividade - aquela relativa ao real do trabalho - é preciso criar condições para colocar em obra dispositivos técnicos que permitam aos sujeitos transformar sua experiência vivida em objeto de uma nova experiência. Trata-se, segundo ele, de abrir uma via para o redoublement ${ }^{7}$ da experiência vivida cujo suporte em vídeo é uma das possibilidades. Assim, o autor nos aponta que o recurso da imagem consiste em uma possibilidade de oferecer ao olhar de trabalhadores e trabalhadoras, seu trabalho à sua frente, em uma espécie de duplicação da situação laboral constituindo, a imagem, em objeto de ação. Configurando pela imagem, uma via para uma nova atividade, pela qual os trabalhadores e trabalhadoras buscam pelos meios de produção, um "[...] meio para si [...]" (CLOT, 2006, p. 132), a imagem em Clínica da Atividade operaria como porta de acesso aos conflitos da atividade.

Mas é no trabalho de Meritan (2008) que

7 Mantivemos a palavra empregada em francês já que sua tradução para redobramento, não parece designar efetivamente o sentido do termo utilizado pelo autor. Parece-nos que a ideia de roudoublement guarda uma potência de ser pensada no rastro do pensamento de Deleuze $(1985,1990)$ enquanto simulacro, enquanto imagem-dessemelhança que nada tem a ver com cópia por ser, justamente, rebelde ao modelo. encontramos elementos mais contundentes para prosseguir em nossas indagações acerca da peculiaridade do dispositivo de imagem para a Clínica da Atividade ou para uma Clínica pela Atividade ${ }^{8}$. Para ela, é de fundamental importância pensar sobre o que é ver já que existem, em seu ponto de vista, dois planos distintos, porém interrelacionados de análise na metodologia da Autoconfrontação: um não-linguageiro e outro linguageiro esse relativo à atividade conversacional travada a partir das imagens. Criticando uma posição de que a imagem produzida para Autoconfrontação consiste em um traço da atividade real, Meritan menciona que ver e falar são meios diferentes empregados em Autoconfrontação chamando a atenção para o fato de que os trabalhadores e trabalhadoras não fazem apenas algo do que dizem a partir das imagens, mas também do que vêem, sendo o que dizem, relativo, também, ao que vêem. Dito de outro modo, para a autora, a atividade de ver mediatiza a atividade de falar, de modo que os fatos do trabalho em imagens não são apenas pretexto ao comentário ou explicação dirigidos ao outro senão que ganham sentidos insuspeitos na experiência de ver.

Tecemos as linhas que seguem considerando que a imagem consiste em um plano específico de análise diferente do plano conversacional e ainda, que nos interessamos pela abertura de novas possibilidades conceituais e metodológicas para a pesquisa no âmbito das Clínicas do Trabalho. Afinal, como operar na pesquisa por entre os planos do ver e do falar? Como eles se conectam na análise da atividade de produção de imagens e desta para a análise da própria atividade de trabalho? 0 quê dessa experiência com as imagens e como tal experiência, se põe em palavras na trama de uma dinâmica conversacional?

E ainda: seria interessante que a produção das imagens para a Autoconfrontação fossem produzidas pelos próprios trabalhadores e não pelo pesquisador? Qual a peculiaridade do percurso de pesquisa no qual os trabalhadores produzem filmes acerca de seu trabalho - dando espaço para uma atividade extraordi-

8 Designamos como Clínica pela Atividade as modalidades de pesquisa acerca da atividade de trabalho que operam por dispositivos metodológicos outros que não a Autoconfrontação e, também, que vêm se empenhando em produções conceituais diferentes, ainda que por entre a Clínica da Atividade. 
nária - e não apenas a gravação de situações laborais ordinárias?

\section{Os percursos da imagem pelo corpo}

Bergson (1999) em suas formulações na obra Matéria e Memória define a matéria com um conjunto de imagens. Para ele, tudo é imagem. Somos imagem; o mundo é imagem. Voltando-se para a matéria antes de sua dissociação operada pelo Idealismo e pelo Realismo, acede a ela enquanto dimensão fluente, em trânsito. Toma a imagem enquanto aquilo que, situada no meio do caminho entre a coisa e a representação que temos dela, é mais do que uma representação e menos do que uma coisa. Bergson lança-nos, assim, à matéria que, como imagem, constitui um plano movente.

Quanto ao corpo, considerado centro de ação pelas afecções ${ }^{9}$, esse influi sobre as imagens, alimentando-as com movimento. Numa espécie de paradoxo movimental o corpo afectivo contém um convite para agir e uma autorização de espera; possui uma tendência à ação ao mesmo tempo que uma simpatia pela permanência na duração, na matéria fluente de variação da vida, influindo desse modo, sobre as imagens exteriores.

Há sempre um processo de duplo traçado das imagens captadas e daquele que as capta, numa espécie de inelutável cisão do ver, como sugere Didi-Huberman (1998). Cisão próxima do que poderíamos chamar de zona de indeterminação, aquela que permite à ação real passar enquanto permanece a ação virtual, que coloca ao corpo uma possibilidade e uma tarefa diante da matéria: projetar-se nela enquanto ação virtual e molecularizá-la, perceptivamente, por uma espécie de consciência vazia (BERGSON, 1999).

Opera-se a chamada percepção pura ${ }^{10}$ tematizada pelo filósofo. Dando-se numa zona de indeterminação, tal percepção que dura

\footnotetext{
9 A afecção para Bergson (1999) guarda uma relação de decorrência em relação à percepção possuindo, ainda, uma di ferença de natureza em relação a ela uma vez que os processos perceptivos se aplicam à extensão das coisas enquanto os afectivos, se crêem como inextensivos.

10 É importante destacar que Bergson se refere às percepções puras e às percepções conscientes, estando as primeiras ligadas a um trabalho de presentificação imagética enquanto a segunda, a um trabalho de representificação imagética.
}

numa terra cega e muda, é capaz de originar imagens radicalmente novas por implicarem numa espécie de obscurescência do objeto; trata-se de uma percepção que se liga às imagens presentificadas, aquelas que têm por necessidade agir, oferecendo-se como "[...] caminho por onde passam em todos os sentidos, as modificações que se propagam no universo [...]" (BERGSON, 1999, p. 33).

É num ir e vir, por entre obscurescências e iluminação que as imagens se presentificam e se (re)presentificam num processo interminável e não cumulativo. É por digressão que se opera, por desvio e por diminuição perceptiva que se processa a imagem; por um ir e vir numa zona de intervalo na qual a matéria se presentifica por um trabalho da percepção pura molecularizada, e se (re)presentifica, pela percepção consciente que temos dela por uma totalidade.

Perfurar a espessura da imagem-percebida pela afecção tendo a memória como travessia a qual, durando, faz sobreviver imagens passadas pela lembrança modificando o presente e fazendo persistir o trajeto, possibilitando, assim, a invenção do mundo. Numa quase simultaneidade com as afecções, a memória exerce, assim, uma função de acréscimo, oferecendo elementos ao traçado do próprio futuro, no sentido de dar corpo à atualização do virtual, figurando, portanto, como veículo de ação e não como substrato de um conhecimento. Trata-se de uma memória que recusando uma função puramente (re)depositária, tem a potencialidade de pôr mundos; de oferecer algo diferente pelo déjà $v u$, porém constituindo um jamais vu.

Bergson (2005) em sintonia com a duração, essa tida como o próprio tecido de que a realidade é feita, permite-nos, então, pelos percursos da percepção, da afecção e da memória, pensar a experimentação da imagem como um perpétuo devir; como algo que se faz e se desfaz, sendo aquilo que nunca é feito. Tomando o real como mudança contínua de formas e, por sua vez a imagem, já que para Bergson o mundo é imagem, quando intentamos fundá-las não fazemos mais do que tomar um instantâneo da transição; de acedê-las pela percepção enquanto estados. As coisas entram umas nas outras, diz Bergson (2005), o que era distendido no espaço se retesa em forma pura, complementa ele, retraindo-se passado, presente e porvir em um momento único que assume 
ares de eternidade. Assim é que uma imagem geradora pode dissolver-se em milhares de imaginações viabilizadas pela contingência em traçados que, hereges, não são mais capazes de restituir aquilo que a gerou.

As qualidades das coisas viram, assim, vibrações reverberantes como aquelas características do olhar dos cegos. Opondo-se umas às outras, tornam-se, assim, travessia para as modificações que caracterizam a duração, exigindo que fechemos os olhos para ver, como sugere Didi-Huberman (1998). Assim, acessamos, então, a não mais que vestígios imagéticos, a aquilo que se anuncia sem aparecer, requerendo um trabalho de tateio no vazio, de experimentação do que não vemos com toda evidência. Acessamos a algo que sem se oferecer em totalidade familiar, ligado ao ganho de alguma coisa, dá-se em fragmentos do estranho que convidam a uma busca, convidam a um toque, por lançarem ao que escapa.

Deleuze $(1985,1990,1992)$ atribui a Bergson o mérito de ter extraído da imagem seu restrito estatuto representativo e, bebendo de sua filosofia, caminha na direção de pensar a imagem como dessemelhança, chegando, ainda, às suas formulações de imagem-tempo. Imagem dessemelhança que nada tem a ver com cópia por ser, justamente, rebelde ao modelo, imagem que deixa de ser segunda em relação ao modelo, figurando em lugar disto, como simulacro, isto é, como dimensão co-extensiva à matéria fluente ou à sua variação.

Simulacro como imagem, imagem como simulacro constitui e reconstitui sempre o começo do mundo enquanto princípio de individuação. Imagem que assim, se refere a um tempo ontológico, àquele relativo a uma dimensão proto-subjetiva anterior a qualquer ser, anterior a qualquer fechamento, porque referidas às forças que thes dão existência.

É nesta direção que Deleuze (1990) analisando o neo-realismo ${ }^{11}$ no cinema, desenvolve elementos para pensarmos as relações entre imagem e pensamento, a partir do que defi-

\footnotetext{
11 Para Deleuze (1990) no neo-realismo o real não era mais representado ou reproduzido, mas visado. Em vez de representar um real já decifrado, o neo-realismo visava um real, sempre ambíguo, a ser decifrado; por isso o plano-sequência tendia a substituir a montagem das representações. Para ele: "O que define o neo-realismo é essa ascensão de situações puramente óticas (e sonoras, embora não houvesse som sincronizado no começo do neo-realismo), que se distinguem essencialmente das situações sensório-motoras da imagemação no antigo realismo [...]" (DELEUZE, 1990, p. 11).
}

ne como imagem-tempo. Pergunta-se ele, se no neo-realismo irromperia um elemento novo o qual impediria a percepção de se prolongar em ação, para assim relacioná-la com o pensamento, e que, pouco a pouco, subordinaria a imagem às exigências de novos signos, que a levassem para além do movimento. No neo-realismo, o personagem tornou-se uma espécie de espectador, diz Deleuze. Ele registra mais que reage, complementa ele. "Está entregue a uma visão, perseguido por ela ou perseguindo-a, mais que engajado numa ação [...]" (DELEUZE, 1990, p. 11).

Do mesmo modo, na imagem oportunizada pelo neo-realismo constitui-se uma situação puramente ótica e sonora, que substitui as situações sensório-motoras enfraquecidas. Diz Deleuze:

Tudo permanece real nesse neo-realismo (quer haja cenário ou exteriores), porém entre a realidade do meio e a da ação, não é mais um prolongamento motor que se estabelece, é antes uma relação onírica, por intermédio dos órgãos dos sentidos, libertos. Dir-se-ia que a ação flutua na situação, mais do que a arremata ou encerra (DELEUZE, 1990, p. 13).

Trata-se de um flutuar na situação, de nela vibrar na situação por uma travessia de oniricidade e fabulação ${ }^{12}$, numa zona ótica e sonora situada antes da ação se formar. Movidas por perturbações que afetam, soltam, desequilibram ou distraem as ligações sensóriomotoras, instaura-se uma crise na imagemação abrindo para imagens bem diversas uma vez que movidas por signos do tipo opsignos e sonsignos ${ }^{13}$.

É por eles que se vê favorecida a transdutividade, quando então, o real pode ser feito imaginário o qual, por sua vez, torna a nos dar realidade. É por eles que acedemos ao vazio, a uma região de proto-forma, de proto-subjetividade, de proto-olhar. Região essa em que as vibrações do mundo são tangíveis pelo tato, por

12 A fabulação é mencionada por Bergson (1999) e foi um termo preciosamente roubado por Deleuze (1997) que o remete ao contato com visões que se elevam aos devires, às potências, aos perceptos e aos afectos. Assim, a fabulação difere da imaginação e de qualquer espécie de projeção do eu.

13 Para Deleuze (1990) as situações óticas e sonoras puras dão lugar a opsignos e a sonsignos, os quais estão sempre fazendo com que os pólos objetivo e subjetivo, real e imaginário se comuniquem assegurando passagens e conversões, tendendo para um ponto de indiscernibilidade. 
um puro tocar, aquele que renunciando as suas funções motoras contenta-se com a preensão háptica, com um toque característico do olhar.

Numa espécie de fusão entre o ótico e o háptico, acede-se, então a um espaço vazio, aquele marcado pela ausência de um conteúdo possível; aquele que prende numa espécie de zona preenchida pela mudança, no tempo, portanto. Desse modo, estamos diante do desaparecimento da imagem-ação em favor da imagem puramente visual, contudo, trata-se de um visual-cego, ou, dito de outro modo, de um visual-corpóreo. Trata-se de uma visão que capta o vazio como lugar de plenitude, posto que preenchido pelo tempo; tempo pleno enquanto forma inalterável preenchida pela mudança; "[...] reserva visual dos acontecimentos em sua justeza [...]", menciona Deleuze (1990, p. 28).

É por esta via que Deleuze busca pensar em como tornar sensíveis o tempo e o pensamento: tornando-os visíveis e sonoros, diz ele. É quando uma situação ótica e sonora não se prolonga em ação ou é induzida por uma ação que ela permite apreender o intolerável, o insuspeitável para, assim, tornar-se visionário. Visionário por operar com imagens puramente visuais e sonoras, as quais como vazio assumem lugar de veículo para o conhecimento e para a ação, para o esquecimento da lógica e dos hábitos de nossa retina.

\section{A imagem videográfica e a análise da atividade}

Philippe Dubois (2006) analisando a especificidade do vídeo afirma ser ele um estado, "[...] estado do olhar e do visível, maneira de ser das imagens. [...] o 'vídeo' não é um objeto (algo em si, com corpo próprio), mas um estado. [...] Um estado-imagem, uma forma que pensa. $O$ vídeo pensa (ou permite pensar) o que as imagens são (ou fazem) [...]" (DUBOIS, 2006 , p. 23). Buscando a etimologia da palavra, Dubois aponta que Video, sem acento, refere-se a um verbo (video do latim videre $=$ eu vejo). Desse modo, video corresponde ao ato mesmo do olhar. Trata-se de um princípio infra-pessoal de eu vejo. Porém, Video em latim não é apenas um verbo, mas um verbo conjugado, que corresponde a primeira pessoa do singular do indicativo presente do ver- bo ser. Dito de outro modo, video é o ato de olhar se exercendo por um sujeito em ação.

É, então, colocando em cena a noção de vídeo como se referindo a uma ação em curso que Dubois põe em destaque uma qualidade do vídeo que nos parece chave para a proposta metodológica da Clínica da Atividade: ela permite um acesso a dimensões do trabalho que se fazem ao vivo, não sendo o eu vi da foto, por exemplo. Tal aspecto parece-nos interessante porque a imagem videográfica permite, ao mesmo tempo, aceder a um objeto e ao ato que o constituiu. Além disto, Dubois (2006) afirma a ambiguidade característica desta imagem: ela é ao mesmo tempo objeto e processo, imagem-obra e meio de transmissão, residindo sua força, justamente nesta precariedade identitária. A imagem em vídeo é como um amálgama fluido de imagem e de olhar, fundidos num ato. Um ato de pensamento, um modo de pensar, diz o autor. Um estado não um objeto, o que também interessa especialmente à metodologia da Clínica da Atividade, pois em sendo-estando, trata-se de uma imagem afeita à concepção, mais do que à recepção.

A imagem videográfica, assim, parece se oferecer à (re)descrição da atividade buscada em tal clínica, potencializando por ela mesma, tanto no ato de produzir a imagem quanto de assisti-la posteriormente, o dinamismo característico da vida que insiste em verter no trabalho. Seguindo o rastro das formulações de Dubois podemos pensar que as especificidades da imagem videográfica enquanto dispositivo para análise da atividade caracteriza-se pela oferta do dinamismo característico da atividade de trabalhadores e trabalhadoras aos seus próprios olhos, se oferecendo assim, como superfície aberta à experimentação. Experimentação enquanto produção de ensaios audiovisuais, esses uma espécie de escritura visual movida pela liberdade do pensamento, pela qual as imagens são produzidas e experimentadas como criação, e não meramente como comunicação de ideias (MACHADO, 2006). Daí derivamos para pensar nos ensaios audiovisuais em vídeo realizados pelos próprios trabaIhadores como um modo de (re)viver/pensar a atividade por imagens valendo-se da potencialidade criadora que se materializa em uma espécie de diálogo imagético. Trata-se antes que de um diálogo, de um modo de dizer ao outro e a si mesmo na experimentação de ver mais do que o trabalho realizado, mas o tra- 
balho por vir, aquele que se anuncia enquanto o que faz problema e perturba os modos estabelecidos de trabalhar.

Brissac (1993) e Goifmann (1998) também auxiliam na tarefa de pensar sobre a especificidade da imagem em vídeo para análise da atividade. Para eles, a videografia leva a uma nova forma de pensar a passagem entre imagens, liberando-as de sua função especular, fazendo da realidade uma zona de indiscernibilidade, perturbadora das continuidades e das totalidades.

Brissac (1993) contribui para pensarmos a ideia de ensaios audiovisuais pelo vídeo. É ele quem diz: "Uma visibilidade anônima nos habita [...] A visão se faz do meio - entre - das coisas [...]" (BRISSAC, 1993, p. 238). Realçando o que define como uma inserção recíproca entre o corpo vidente e o visíve/14, destaca o vídeo como ponto de interseção entre novas formas de escrita e um novo corpo para as imagens, fazendo aparecer aquilo que não se pode filmar: a imagem entre os corpos. O autor tematizando algumas das modalidades de trânsito possíveis proporcionadas pelo vídeo - ressaltando as possibilidades de manipulação e edição -, destaca que a agitação que estria a imagem permite ver de outro modo o que é nítido, bem como a tensão que atravessa a paisagem. Por outro lado, a interrupção da imagem permite introduzir uma foto no quadro para produzir um efeito de suspensão, uma parada que nos dá tempo pra acrescentar algo à imagem.

Outro modo de entrecruzar as imagens analisado pelo autor é a experimentação com a velocidade, através do uso do slow-motion e da sequência de cortes rápidos. "A mudança de velocidade, tentativa analítica de ir mais devagar para ver melhor, é uma forma orgânica, física de decomposição da imagem [...]", diz ele (BRISSAC, 1993, p. 245). Tal interpenetração das imagens, seria uma nova forma de montagem ficcional e o vídeo, faria aparecer aquilo que não se pode filmar, a imagem entre os corpos.

Perguntando-se sobre como fazer uma imagem, aponta um caminho: sendo a trajetó-

\footnotetext{
14 Destacamos que Brissac associa o visível a uma qualidade relativa à superfície e não a profundidade da imagem, sugerindo que o plano do vidente estaria aí relacionado. Pensamos numa inversão destes termos: para nós, o visível refere-se ao plano do profundo que recobrimos pelo universo de representações, enquanto o vidente relaciona-se à superfície, ao plano de dispersão aberto à hetereogeneidade e a presentificação imagética.
}

ria do olhar errática e descontínua, a captação imagética deveria adotar - "[...] pela câmera lenta - o mesmo traço hesitante e aleatório do pintor [...]" (BRISSAC, 1993, p. 247). Trata-se de quebrar a organização ótica convencional, substituindo uma geometria ótica por uma linha manual que o olho mal consegue acompanhar. Trata-se de passar da visão ao tato por uma linha que não vai de um ponto a outro, mas passa entre os pontos traçando formas que até podem ser figurativas, mas que não têm mais laços figurativos, pois o que as liga é o movimento.

Para Goifman (1998) as imagens videográficas não são mais expressões de uma geometria, mas de uma geologia, ou seja, de uma inscrição do tempo no espaço, salientando que a produção de imagens e sons permite o acesso a uma estilística das falas dos participantes da pesquisa, em situação de análise. Diz ele que se a escrita propicia o recorte de palavras significativas dentro de um contexto gramatical, a captação sonora expande esse contexto até a lógica da oralidade. Assim, Goifman (1998) coloca em cena outras dimensões, também relevantes para análise tais como, o tom das vozes, os gestos, os movimentos e os silêncios de palavras que oferecem, no entanto, cenas em seu lugar. Além disto, destaca que a captação em vídeo possibilita a experimentação de um alargamento temporal da observação empírica, devido à possibilidade que se cria de observação repetida e diferenciada das imagens, oferecendo possibilidades tais como pausas e slow-motion.

Retornando a proposta metodológica da Autoconfrontação poderíamos pensar que o vídeo possibilita, sobremaneira, um acesso aos ruídos imagéticos que, perturbando a imagem, podem vir a produzir um deslocamento dos compromissos com a atividade prescrita produzindo obstáculos no âmbito da atividade real e lançando-a ao plano dos seus virtuais? Fazendo aparecer a imagem entre os corpos, pode favorecer uma porosidade entre eles que perturbe contornos identitários relativos tanto a si mesmo quanto à atividade? A captação sonora que o vídeo oportuniza - expandindo o contexto gramatical até a lógica da oralidade -, pode figurar como um componente fundamental para a estilização do gênero da atividade, por perturbar seus invariantes?

A proposta em Clínica da Atividade consiste em abordar dialogicamente a situação, mo- 
vida por uma compreensão ativa, fundada ao mesmo tempo, em hipóteses explicativas e em uma análise de sua própria atividade na situação, para transformar essa última. Trata-se de fazer à atividade dos sujeitos novas perguntas que eles mesmos não se fariam, disparando um processo indagativo acerca da atividade, no Meio Associado à pesquisa, para fazer aflorar a variabilidade do processo de trabalho.

Pela Autoconfrontação Simples e Cruzada, propõe-se, então, um campo de experimentação que constitui o que se entende como atividade dirigida ${ }^{15}$, numa superposição da atividade que se busca compreender. Superposição porque a experimentação pela linguagem vivenciada está a serviço da criação de um outro modo de pensar e sentir relativo à atividade, a partir da perspectiva dos sujeitos.

Nesta linha, destaca-se que a mudança de destinatário modifica a análise, dando um acesso diferente ao real da atividade do sujeito. Afirmando-se a Autoconfrontação como uma metodologia de acesso ao real da atividade, Clot (2006) parece-nos aqui apontar um ponto interessante: o lugar privilegiado de acesso aos virtuais do trabalho, os quais, pensamos - constituem o real da atividade, a esfera que transborda sua atualização no plano da atividade - está localizado na verbalização, no comentário dos dados videografados dirigidos a um outro, que não ele, no caso, ao pesquisador e aos pares, buscando agir sobre eles.

A partir daí, como podemos pensar esse percurso no caso de os próprios trabalhadores serem os produtores das imagens de cenas ordinárias (tal como propõe a Autoconfrontação) ou de filmes (atividade extraordinária) acerca de sua atividade? Estaríamos criando chances, pelo vídeo, para uma certa maneira de se manifestar para si mesmo, consistindo numa oportunidade de se mostrar, fazendo aparecer seu próprio rosto perto do outro? Tratarse-ía de algo como tomar os vídeos enquanto possibilidade de um olhar que se lança sobre o destinatário das imagens (pela missiva que ele recebe, se sente olhado), bem como uma maneira de se oferecer ao seu olhar através do que lhe é mostrado sobre si mesmo? Nesse jogo de abertura ao outro sobre si mesmo,

15 Clot (2006) define Atividade Dirigida como sendo uma situação na qual a linguagem, longe de ser para o sujeito apenas um meio de explicar aquilo que se faz ou aquilo que se vê, torna-se um meio de levar o outro a pensar, a sentir e a agir segundo a perspectiva do sujeito. impulsionaríamos uma experiência de desalojamento próxima de uma estética da vida que lançaria o trabalho a sua reinvenção?

Foi nesta direção que experimentamos a proposta de um modo específico de análise da atividade, na pesquisa intitulada Entre Prisões da Imagem, Imagens da Prisão - um dispositivo tecnopoético para uma clínica do trabalho ${ }^{16}$, onde agregamos à linguagem verbal sobre tais imagens como meio de verbalização da ação - tal como proposto na Autoconfrontação -, a produção de imagens videografadas, digitalizadas e abertas à imersão por agentes penitenciárias. Tratou-se de pôr em cena uma espécie de pensar em imagens pelo qual concentramo-nos nas possibilidades plásticas dos recursos digitais de imagem para criação de uma experiência imersiva aberta à perturbação de sentidos e à invenção de mundos, a ser relançada ao pesquisador e aos pares, como oportunidade de acionar outros modos de pensar, sentir e agir no trabalho.

Diz Clot $(2006,2008)$ que é pelo outro que o trabalhador encontra algo de novo em si, pela dissonância entre as próprias emoções e percepções suas e as do outro, seja esse par ou pesquisador, valendo-se do emprego de imagens em vídeo para elucidarem para si mesmos e para o outro, as questões que surgem durante o (des)envolvimento da atividade, tendo em vista que, no momento de assistilas, a atividade já é outra, pondo-se, igualmente em análise. Desse modo, Clot (2006) adverte para o fato de que a atividade não está à espera de explicação, e sim de implicação, pensamos, caso contrário, o caminho de pesquisa tenderia para uma recuperação dos invariantes da atividade, desconsiderando-se o (des)envolvimento da mesma, pela análise.

O referencial teórico-metodológico da Clínica da Atividade parece reconhecer, portanto, que a experimentação imagética, além da situação de estarem frente a frente, trabalhadores e trabalhadoras, bem como eles (as) e pesquisadores, produz uma nova situação para análi-

16 Esta pesquisa consiste em nossa tese de doutorado na qual exploramos as peculiaridades da atividade de produção de imagens sobre o trabalho prisional ressaltando as imbricações entre ver, pensar e falar, o que caracterizou uma vertente metodológica no percurso da tese. Dedicamonos ainda, a uma vertente teórica, pela qual operamos um tencionamento conceitual visando abrir veredas no que se refere à construção de possibilidades para uma Clínica do Trabalho valendo-nos das ferramentas analíticas da Filosofia da Diferença, da Ergologia e da Clínica da Atividade (AMADOR, 2009). 
se. A Clínica da Atividade propõe sustentar seu movimento de análise da atividade por intermédio de seu próprio (des)envolvimento e pela verbalização sobre ela, entre os pares e entre eles e os pesquisadores. Pela Autoconfrontação se estabelece "[...] um ciclo entre aquilo que os trabalhadores fazem, aquilo que eles dizem daquilo que fazem e, por fim, aquilo que eles fazem daquilo que dizem [...]", Clot (2006, p. 136). Em nossa pesquisa pela produção fílmica, em certa sintonia com a busca do autor, propusemos uma experimentação que agrega um sutil diferencial que se localiza, fundamentalmente, naquilo que as trabalhadoras fazem, no que mostram/imagetizam do que fazem; no que experimentam pelo que mostram-imagetizam na esfera videográfica e dos vídeos digitalizados, e no que fazem do que mostram/imagetizam.

Visando a experimentação imagética, nosso objetivo consistiu em explorá-la como dispositivo para a criação na atividade, propósito esse também presente na Clínica da Atividade (CLOT, 2006). Isto, pelo fato do autor salientar que a finalidade da análise não é remediar erros ou reproduzir a experiência e sim, deixar nascer a ação, dar-lhe passagem pelo curso da vida que verte no trabalho.

A experiência de trabalho já é dotada de dinamismo quando da realização da própria atividade, mas parece-nos revitalizar-se pelo agenciamento de uma nova situação vivida criada com os recursos da videografia. A pesquisa em Clínica da Atividade requer, assim, meios que visando aceder a uma esfera movente, não levem ao risco de fixá-la. Há que se possibilitar, então, uma metodologia entendida como uma prática. Uma prática clínica para operar uma Clínica pela Atividade, clínica que interessada nas rupturas no curso do trabalho antes que nas zonas de estabilidade operatória, aposta na potência vital do trabalho que seduzida pelo devir, anda por estradas insólitas em busca por terra nova em um empreendimento eminentemente poético.

Não se trata de pensar que os trabalhadores e trabalhadoras prosseguem trabalhando por que instituem normas para tanto, mas justamente, porque as transformam num processo incessante de busca por expansão de seu poder de agir, como mesmo deixa entrever Clot (2005, p. 159-160) no trecho a seguir: "[...] tal como a arte, uma forma de transformar nossa vida, uma maneira de viver outra coisa, um recurso para descobrir aquilo de que somos capazes [...]".
Em nossa pesquisa buscamos, então, o emprego das imagens produzidas pelas próprias trabalhadoras como meio para revitalizar a atividade e de dizer dela ao outro; como um meio para imergir nelas próprias, acionando uma experiência de dizer, também, ao outro, em si mesmo. Pondo relevo muito mais numa geografia $^{17}$ do que numa história, nossa pesquisa visou explorar não apenas a distância entre o Trabalho Prescrito e o Real, mas a criação de um ambiente de imagens para habitar, como via de acesso aos virtuais do trabalho. Assim, além das controvérsias entre o real e o possível (CLOT, 2006, 2008) no curso da atividade visamos traçar os delizes por entre o virtual e o atual. Destacamos este aspecto a partir de Deleuze e de sua distinção entre possível e virtual. Para ele o possível opõe-se ao real sendo o processo do possível, da ordem da realização. O virtual ao contrário, não se opõe ao real porque ele é pleno de realidade sendo seu processo a atualização. Diz ainda o autor:

A atualização do virtual, ao contrário, sempre se faz por diferença, divergência ou diferençação. [...] No virtual, a diferença e a repetição fundam o movimento da atualização, da diferençação como criação, substituindo, assim, a identidade e a semelhança do possível, que só inspiram um pseudomovimento, o falso movimento da realização como limitação abstrata [...] (DELEUZE, 2006b, p. 299-300).

Aliando dois planos - imagético e verbal - , enfatizamos a imagem como meio de expressão da ação, procurando sintonizar com o plano implicativo deste processo, mais do que com a dimensão explicativa lançada pelas agentes prisionais acerca de sua atividade, no caso da pesquisa citada. Interessou-nos, além das virtualidades viabilizadas pela verbalização de umas às outras, aquelas relativas à experimentação pelo olhar no ambiente criado pelas imagens videografadas e digitalizadas, tomando-o como dimensão-chave da atividade dirigida, isto é como um meio de levar o outro e a si mesmo, a pensar, a sentir e a agir diferentemente, mas também, estabelecendo um plano

17 Falamos em geografia, pensando que o percurso da Clínica da Atividade tangencia com um modo de pensamento sobre a atividade que a toma como terra a ser absorvida pelo pensamento, instaurando desterritorializações que afirmam a criação de uma terra nova por vir, de um modo inventado de exercê-la, tal como sugerem Deleuze e Guattari (1992) quando se dedicam a pensar sobre geofilosofia. 
de relação que ultrapassa o vivido no trabalho por referir-se a sensações e devires.

Retomamos Deleuze $(1985,1990)$ em suas elaborações a respeito da narração no cinema a qual, para ele, não é mais que uma consequência de imagens aparentes nelas mesmas e de suas combinações diretas. Ela é uma consequência de imagens sensíveis nelas mesmas, ou seja, engaja uma espécie de signos prélinguísticos, mas cuja a língua e os enunciados linguageiros vão depender. De uma narração pela montagem no cinema clássico, a uma narração por mostração no cinema moderno, para Deleuze (1990), toda uma peculiaridade narrativa em relação à imagem animada do cinema é anunciada.

Interessando-nos o potencial clínico da experimentação de produção de imagens para uma análise da atividade de trabalho e pensando-as como ensaios audiovisuais (DUBOIS, 2006), isto é, como um modo de, por imagens, mais que comunicar, mostrar-dizer criando, perguntamo-nos como se opera essa experiência pela montagem e pela mostração imagéticas? Anunciando a narrativa como algo que depende da experimentação da matéria-movimento que a imagem animada oferece aos nossos olhos e corpos, estaria justo aí, o trabalho a fazer durante o percurso da pesquisa da atividade: acompanhar o traçado deste plano de experimentação da produção de imagens e da narrativa que neste movimento é suscitada?

Entendendo que a imagem gera a palavra e não apenas a suporta, que do não-linguístico ${ }^{18}$ das imagens produzidas do trabalho produz-se um discursivo sobre a atividade, é então desse percurso que podemos nos ocupar, onde a imagem é pensada como meio de elevar o olhar para além do empírico fazendo nascer o visionário, tornando visíveis as forças que na e pela imagem, não são visíveis por si mesmas. Tratase de incursionar por um dispositivo para ver outramente e daí, produzir outra coisa no plano do pensamento apostando em uma espécie de expansão do poder de ver e por aí, expandir o poder de agir.

Tomando as imagens como complexos de

18 Empregamos a expressão não-linguístico para as imagens a partir de Sauvagnargues (2005), comentadora de Deleuze. A autora mostra que o filósofo ao se dedicar a pintura e ao cinema em sua obra, vai se ocupar de uma teoria dos signos não- linguísticos ou não-discursivos. Para ele tais artes não são redutíveis a significação discursiva razão pela qual, valemo-nos das formulações deleuzianas acerca da imagem para pensarmos a imagem videográfica. sensações - não redutíveis à significação discursiva - que estimulam o pensamento, procuramos remontar por tal experiência sensorial e auditiva, aos dados de problema que as imagens colocam em relação à atividade. A imagem como composto de afectos e perceptos, como complexo de forças, de variação é aqui considerada como realidade, como literalidade, como matéria aberta à percepção que sem colocar em obra palavras significantes em uma ordem sintática, possui um efeito particular sobre o pensamento. Trata-se de incursionar por um caminho pelo qual se vai da imagem videográfica experimentada à palavra, por elementos que, contudo, a ela não se remetem; de imergir por uma espécie de estética de criação visual pela experimentação de uma dimensão extraordinária relativa ao trabalho capaz de pôr questões à sua dimensão ordinária.

Assim, a dimensão clínica do trabalho no âmbito de uma Clínica pela Atividade referese à perturbação do plano discursivo que suporta o gênero da atividade, pela própria característica da matéria signalética da imagem animada. É esta distância que pode abrir à colocação de problemas, ao fluxo do pensamento em relação à atividade real e ao real da atividade, pensamos. Distância que, por sua vez, reivindica espaço em uma esfera discursiva no plano da linguagem.

Mais do que o quê se vê, interessa-nos o ver em atividade para dele traçar os modos como o olhar surpreende-se ou não nesta experimentação de sua própria atividade de trabalho por imagens. Dissemos anteriormente que Yves Clot (2008) afirma serem duas, as orientações da análise da atividade: o real do trabalho e o movimento dialógico, buscando tal real, no plano desse último de modo a manter-se na esfera conversacional. Procuramos assinalar neste texto que a imagem videográfica na Autoconfrontação ou em outras modalidades de emprego da imagem na pesquisa da atividade, desempenha um papel decisivo e peculiar nesse processo ao propiciar uma experimentação que ultrapassa o plano linguageiro onde se assenta o gênero da atividade. Como tal, a imagem mostra-se potente para instaurar derivas na análise da atividade por elementos que provêm de um outro lugar, de um não-lugar, talvez, aquele que pertencendo à esfera do sensível ainda não encontrou as palavras. 


\section{Referências}

AMADOR, Fernanda Spanier. Entre Prisões da Imagem, Imagens da Prisão: um dispositivo tecno-poético para uma Clínica do Trabalho. 2009. Tese (Doutorado) - Programa de Pós-Graduação em Informática na Educação, Universidade Federal do Rio Grande do Sul, 2009, Porto Alegre, BR-RS.

BAKHTIN, Mikhail. Marxismo e Filosofia da Linguagem. São Paulo: Hucitec, 1988.

BERGSON, Henri. Matéria e Memória. São Paulo: Martins Fontes, 1999.

. A Evolução Criadora. São Paulo: Martins Fontes, 2005.

BRISSAC, Nelson. Passagens da Imagem: pintura, fotografia, cinema, arquitetura. In: PARENTE, André (Org.). Imagem-Máquina: a era das tecnologias do virtual. Rio de Janeiro: Ed. 34, 1993. P. 237-252.

CANGUILHEM, Georges. Meio e Normas do Homem no Trabalho. Pro-posições, Campinas, v. 12, n. 2/3, p. 35-36, jul./Nov. 2001.

CLOT, Yves. Le travail sans l'homme?: pour une psychologie des millieux de travail et de vie. Paris: Ed. Découverte, 1985.

. A Função Psicológica do Trabalho. Petrópolis, RJ: Vozes, 2006.

- A Clínica da Atividade: uma metodologia de intervenção no trabalho como atividade coletiva e dialógica. [S.I.: s.n.], 2007. Curso ministrado por Yves Clot na Universidade Federal Fluminense, Rio de Janeiro. Material não-publicado.

CLOT, Yves. Travail et pouvoir d'agir. Paris: Presses Universitaires de France, 2008.

DELEUZE, Gilles. A Imagem-Movimento: Cinema 1. São Paulo: Ed. Brasiliense, 1985.

A Imagem-Tempo: Cinema 2. São Paulo: Ed. Brasiliense, 1990.

Conversações. São Paulo: Ed. 34, 1992.

. Crítica e Clínica. São Paulo: Ed. 34, 1997.

. Espinosa: filosofia prática. São Paulo: Escuta, 2002.

; GUATTARI, Félix. O que é Filosofia? Rio de Janeiro: Ed. 34, 1992.

DUBOIS, Philippe. Cinema, Vídeo, Godar. São Paulo: Cosac Naify, 2006.

DIDI-HUBERMAN, Georges. O que Vemos, o que nos Olha. São Paulo: Ed. 34, 1998.

DO EIRADO, André. O Hábito do Ponto de Vista Ontológico e a Produção da Subjetividade. Revista do Departamento de Psicologia da UFF, Niterói, v. 10, n. 1, p. 4-8, 1998.

DURRIVE, Louis. Introdução. In: SCHWARTZ, Y.; DURRIVE, L. (Org.). Trabalho e Ergologia: conversas sobre a atividade humana. Niterói: EDUFF, 2007. p. 19-20.

FAITA, Daniel. L'image animée comme artefact dans lê cadre méthodologique d'une analyse clinique de I'activité. @ctivités: revue életronique, Paris, v. 4, n. 2, p. 3-15, 2007. http://www.activites.org/v4n2/v4n2.pdf 
FERREIRA, Mário César. Atividade, Categoria Central na Conceituação de Trabalho em Ergonomia. Revista Aletheia, Canoas, n. 11, p. 71-82, 2000.

FRANÇA, Maristela. No Princípio Dialógico da Linguagem, o Reencontro do Homo Loquens com o Ser Humano Industrioso. In: FIGUEIREDO, Marcelo; ATHAYDE, Milton; BRITO, Jussara; ALVAREZ, Denise. (Org.). Labirintos do Trabalho: interrogações e olhares sobre o trabalho vivo. Rio de Janeiro: DP\&A, 2004. P. 115-121.

GOIFMAN, Kiko. Valetes em Slow Motion: a morte do tempo na prisão: imagens e textos. Campinas, SP: Ed. da UNICAMP, 1998.

LHUILIER, Dominique. Cliniques du Travail. Paris: Éd. Érès, 2006.

MACHADO, Arlindo. Apresentação à Obra de Dubois. In: DUBOIS, Philippe. Cinema, Vídeo, Godard. São Paulo: Cosac Naify, 2006. P. 11-28.

MERITAN, Agnès. L'image animée em clinique de l'activité: objet, instrument, discours. Memoire de master recherche. Paris: CNAM, 2008.

SAUVAgnARgUeS, Anne. Deleuze et l'art. Paris: Presses universitaires de France, 2005.

SPINOZA, Benedict. Ética. Belo Horizonte: Autêntica Ed., 2008.

Recebido em junho de 2010.

Aprovado para publicação em agosto de 2010.

Psicóloga, Doutora em Informática na Educação pela Universidade Federal do Rio Grande do Sul (UFRGS)/Porto Alegre-RS/ Brasil, Pós-doutora em Educação pela UFRGS. Professora Adjunta do Departamento de Psicologia Social e Institucional do Instituto de Psicologia da UFRGS.

Email: feamador@uol.com.br. 